\title{
AEROSOL PROFILING DURING THE LARGE SCALE FIELD CAMPAIGN CINDI-2
}

Arnoud Apituley ${ }^{1, *}$, Michel Van Roozendael ${ }^{2}$, Andreas Richter ${ }^{3}$, Thomas Wagner ${ }^{4}$, Udo Friess $^{5}$, Francois Hendrick ${ }^{2}$, Karin Kreher ${ }^{6}$, Jan-Lukas Tirpitz ${ }^{5}$ and CINDI-2 Participants ${ }^{7}$

${ }^{1}$ Royal Netherlands Meteorological Institute (KNMI), The Netherlands, *apituley@knmi.nl

${ }^{2}$ BIRA-IASB, Brussels, Belgium

${ }^{3}$ IUP-Bremen, Germany

${ }^{4}$ MPIC, Mainz, Germany

${ }^{5}$ IUP-Heidelberg, Germany

${ }^{6}$ Bodeker Scientific, Alexandra, New Zealand

${ }^{7}$ Various countries world-wide

\section{ABSTRACT}

For the validation of space borne observations of $\mathrm{NO}_{2}$ and other trace gases from hyperspectral imagers, ground based instruments based on the MAXDOAS technique are an excellent choice, since they rely on similar retrieval techniques as the observations from orbit. To ensure proper traceability of the MAXDOAS observations, a thorough validation and intercomparison is mandatory. Advanced MAXDOAS observation and retrieval techniques enable inferring vertical structure of trace gases and aerosols. These techniques and their results need validation by e.g. lidar techniques.

For the proper understanding of the results from passive remote sensing techniques, independent observations are needed that include parameters needed to understand the light paths, i.e. in-situ aerosol observations of optical and microphysical properties, and essential are in particular the vertical profiles of aerosol optical properties by (Raman) lidar.

The approach used in the CINDI-2 campaign held in Cabauw in 2016 is presented in this paper and the results will be discussed in the presentation at the conference.

\section{INTRODUCTION}

Ground based and spaceborne hyperspectral instruments for observations of $\mathrm{NO}_{2}$ and other trace gases rely on similar retrieval techniques. In both cases, retrievals take into account the light path of scattered sunlight though the entire atmosphere (see Fig.1). In case of high aerosol load close to the surface, this will dominate the light path and therefore bias the sensitivity of the measurement to this part of the atmosphere. Since MAXDOAS instruments are relatively low cost and can be operated autonomously almost anywhere, they are credible candidates to form a world-wide ground based reference network for satellite observations. To ensure proper traceability of the MAXDOAS observations, a thorough intercomparison is mandatory.

With the imminent launch of Sentinel-5 Precursor/TROPOMI (6), with a nadir pixelsize of $3.5 \times 3.5 \mathrm{~km}^{2}$, and recent developments in MAXDOAS instruments there was a need for

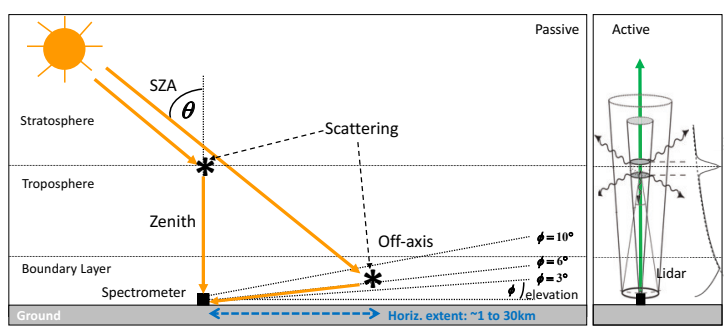

Figure 1: Schematic of light paths for MAXDOAS (left) and for lidar (right). Note that the effective footprint of the passive MAXDOAS observation extends multiple kilometers (similar to satellite observations), while the lidar footprint is much smaller. 


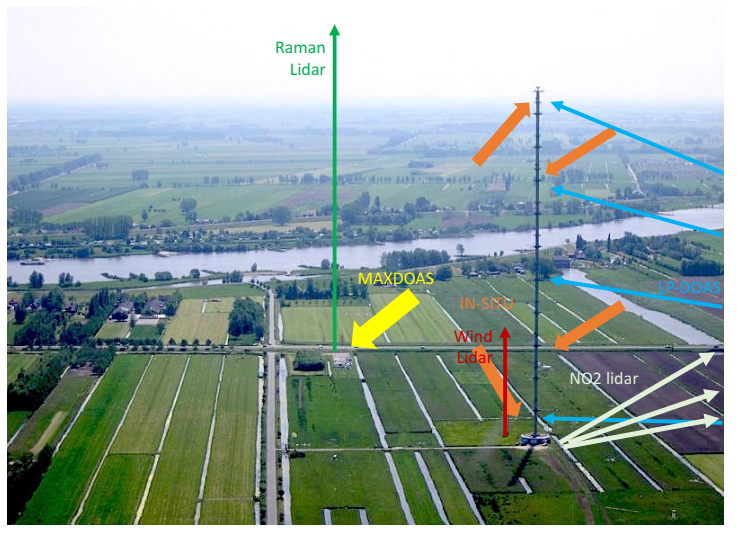

Figure 2: Aerial view of the CESAR site near Cabauw, showing the location of the main instrumentation of the campaign.

CINDI-2. This campaign was completed in September 2016 and had the goals to: 1) Asess the consistency of slant column measurements of key target species $\left(\mathrm{NO}_{2}, \mathrm{O}_{3}, \mathrm{O}_{4}\right.$ and $\left.\mathrm{HCHO}\right)$ relevant for the validation of S5P and the future ESA atmospheric Sentinels, from a large number of DOAS and MAXDOAS instruments from all over the world, and 2) study the relationship between remote-sensing column and profile measurements of those species and reference measurements of the same species.

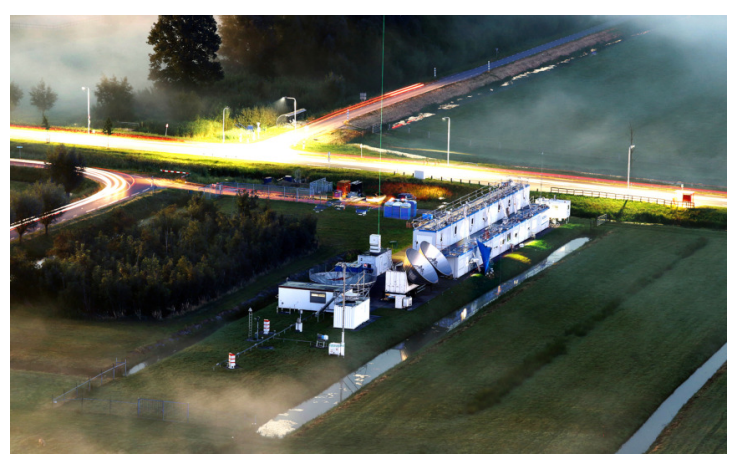

Figure 3: Picture of the CINDI-2 observation site. The MAXDOAS instruments were placed on the roof of temporary containers situated at the Remote Sensing Site of the CESAR Observatory where the Raman lidar and ceilometer are permanently located.

\section{CAMPAIGN DESIGN}

A feature of recent MAXDOAS developments is the use azimuthal scanning, in addition to elevation scanning such as in e.g. the PANDORA type of instruments (3). This, and the number of participating instruments, that expanded to 42 , posed a challenge to the design of the CINDI-2 campaign.

The Cabauw Experimental Site for Atmospheric Research (CESAR) site in centre of The Netherlands (1) was the stage of the Cabauw Intercomparison of Nitrogen Dioxide Measuring Instruments (CINDI) in June-July 2009 (4) and again for the second campaign, CINDI-2, in 2016. Cabauw was chosen because the flat terrain offers a free view of large parts of the horizon, needed to accommodate the viewing geometry of the MAXDOAS observations. The location is under influence of both clean as well as polluted airmasses. This gives a wide range of possible trace gas concentrations and mixtures.

Furthermore, at CESAR a wide range of observations are routinely carried out that fulfil the requirement to provide the background necessary for unraveling the differences between the observations from different MAXDOAS instruments that can be quite diverse in design and data treatment. These observations include parameters needed to understand the light paths, i.e. in-situ aerosol observations of optical and microphysical properties, as well as vertical profiles of aerosol optical properties by (Raman) lidar (2). In addition, vertical profiles of $\mathrm{NO}_{2}$ were provided by the unique $\mathrm{NO}_{2}$ sonde (5), and a $\mathrm{NO}_{2}$ lidar system (7). In situ observations of aerosol scattering and absorbing properties, as well as microphysical properties were made in collaboration with the ACTRIS2 project. The placement of the instruments on the Cabauw site is schematically shown in Fig.2 and a picture of the remote sensing site is shown 


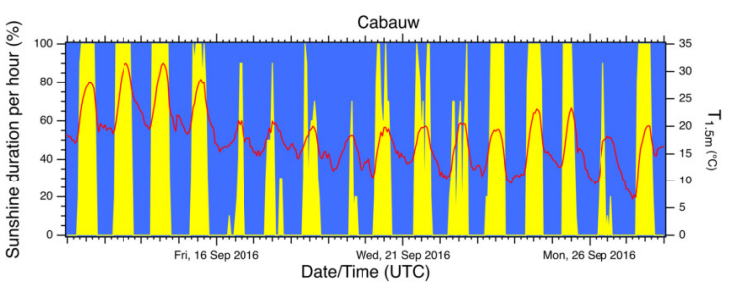

Figure 4: General meteorological conditions during the campaign main intercomparison phase between 12 and 28 Sept. 2016.

in Fig.3. Here, we focus on the aerosol profile. The $\mathrm{NO}_{2}$ profiles are discussed in a paper by $\mathrm{S}$. Berkhout at ILRC28.

\section{FIRST RESULTS}

Due to favourable weather conditions for making MAXDOAS and lidar observations, i.e. absence of clouds as shown in Fig.4, a very interesting dataset has been collected, where most of the instruments were able to provide data.

An example of an aerosol profiling case is shown in Fig.5 and 6. Fig.5 shows the (preliminary) MAXDOAS aerosol extinction profiles retrieved for $477 \mathrm{~nm}$. The extinction peaks between 0.5 and $1.5 \mathrm{~km}$ above ground while some structure in the aerosol profile is present for the results from all groups below $1 \mathrm{~km}$. The peak value of the extinction is about $0.3 \mathrm{~km}^{-1}$. Lidar data for the same day are shown in Fig.6, where the top panel shows the 24-h aerosol profile from the Lufft CHM15k ceilometer and the bottom left in the figure shows the Raman lidar range corrected signal. The lower right shows the Raman lidar backscatter and extinction profiles, as well as the lidar-ratio and Ångström coefficient. From the lidar extinction profile at $355 \mathrm{~nm}$ it can be seen that extinction profile peaks at $\approx 2.5 \mathrm{~km}$ at a value of $\approx 0.3 \mathrm{~km}^{-1}$. So, while the peak extinction values are very similar, the shape of the profile shows marked differences. The analysis of the CINDI-2 data is ongoing and the latest stage of development will be shown at the conference.

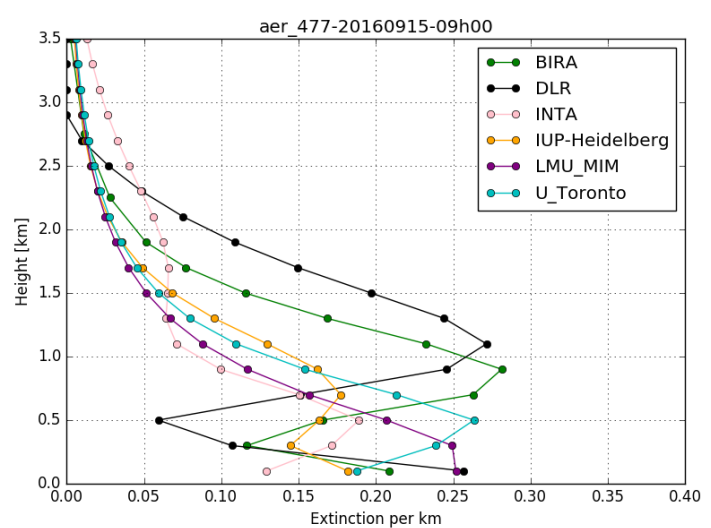

Figure 5: Example of MAXDOAS aerosol profile retrieval at $477 \mathrm{~nm}$ for 15 Sept. 2016 around 9 UTC from various participating groups. Note that these are preliminary results.

\section{CONCLUSIONS}

The CINDI-2 campaign conducted in Sept. 2016 in Cabauw was successful due to well functioning instruments and thanks to favourable weather conditions. A valuable dataset was collected. Preliminary data analysis shows that the observations are suitable for study of the (aerosol) profile retrieval from MAXDOAS observations. The lidar measurements carried out the the facility are key data for the evaluation of the results.

\section{ACKNOWLEDGEMENTS}

The CINDI-2 campaign was supported by ESA, the Netherands Space Office (NSO) and ACTRIS-2 (H2020-INFRAIA 654109).

\section{References}

[1] A. Apituley, et al. Overview of research and networking with ground based remote sensing for atmospheric profiling at the cabauw experimental site for atmospheric research (cesar) the netherlands. In Proceedings IGARSS 2008, 


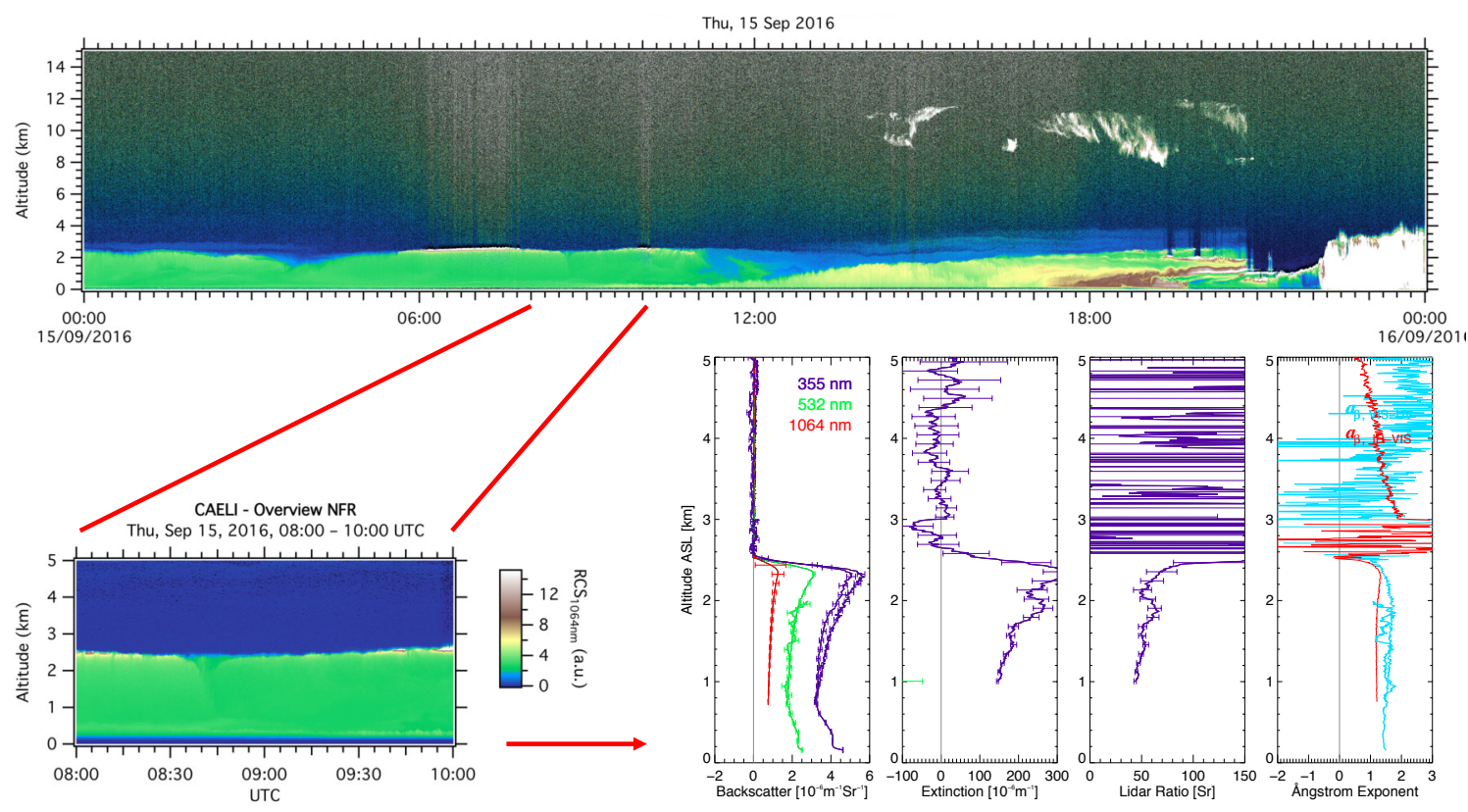

Figure 6: Example of a diurnal CHM15k ceilometer observation for 15 Sept. 2016 (top) and a daytime multi-wavelength Raman lidar observation between 8-10 UTC (bottom). In the lower-right panel, the retrieved backscatter and extinction profiles are shown. Note that these are daytime measurements.Therefore, only the $355 \mathrm{~nm}$ Raman extinction profile is available. The lidar ratio above the aersol layer that extends to about $2.5 \mathrm{~km}$ appears as noise, since the extinction fluctuates around zero.

Boston, Massachusetts, volume III, pages 903906, 2008.

[2] A. Apituley, et al. Performance Assessment and Application of Caeli - A high-performance Raman lidar for diurnal profiling of Water Vapour, Aerosols and Clouds. In A. Apituley, H. Russchenberg, and W. Monna, editors, Proceedings of the 8th ISTP, pages S06-O10, 2009.

[3] J. Herman, et al. NO2 column amounts from ground-based Pandora and MFDOAS spectrometers using the direct-sun DOAS technique: Intercomparisons and application to OMI validation. Journal of Geophysical Research: Atmospheres, 114(D13):n/a-n/a, 2009. D13307.

[4] A. J. M. Piters, et al. The Cabauw Intercomparison campaign for Nitrogen Dioxide mea- suring Instruments (CINDI): design, execution, and early results. Atm. Meas. Tech., 5(2):457485, 2012.

[5] W. W. Sluis, et al. The development of a nitrogen dioxide sonde. Atmospheric Measurement Techniques, 3(6):1753-1762, 2010.

[6] J. Veefkind, et al. TROPOMI on the ESA Sentinel-5 Precursor: A GMES mission for global observations of the atmospheric composition for climate, air quality and ozone layer applications. Remote Sensing of Environment, 120(0):70 - 83, 2012.

[7] H. Volten, et al. NO2 lidar profile measurements for satellite interpretation and validation. J. Geophys. Res., 114, 122009. 